\title{
Laparoscopic cystostomy in pigs: Technique and comparison with traditional open cystostomy for surgical stress
}

\author{
Hua Zhang, Zhi-fei Zhou, Jian-tao Zhang, Shi-xia Zhang, Hong-bin Wang \\ Northeast Agricultural University, College of Veterinary Medicine, Harbin, China
}

Received May 16, 2014

Accepted September 17, 2014

\begin{abstract}
Cystostomy is a common procedure in veterinary surgery. We describe a technique for laparoscopic cystostomy (LC group; $\mathrm{n}=7$ ) in Bama miniature pigs and compare the surgical stress induced by this procedure to open cystostomy ( $\mathrm{OC}$ group; $\mathrm{n}=7$ ). A three-portal approach was used for laparoscopic cystostomy. First, we placed 2 simple interrupted sutures between the ventral body wall and urinary bladder. Then, a purse-string suture was placed in the urinary bladder wall, approximately $1 \mathrm{~cm}$ cranially to the two sutures. A stab incision was made at the center of the purse-string suture and a 12-F Foley catheter advanced into the urinary bladder; the suture was then pulled tightly and tied. Again, two interrupted sutures were placed $1 \mathrm{~cm}$ cranially to the catheter, between the ventral body wall and the bladder, to establish cystopexy. The extracorporeal portion of the catheter was fixed to the skin by a finger-trap suture. Blood samples were collected to measure the white blood cell count and serum concentrations of cortisol, interleukin-6, and C-reactive protein; follow-up laparoscopy was performed 1 month after the surgery. Laparoscopic cystotomy was successfully performed in all the pigs; the mean operating time was $43 \pm 5 \mathrm{~min}$. The levels of the stress markers reflected a lower stress response for LC than OC. Thus, LC appears to be better than OC both in terms of technique and physiological responses elicited, and may be more suitable than $\mathrm{OC}$ in the creation of experimental animal models for investigations on urinary diseases and those requiring diversion of urine flow.
\end{abstract}

Minimally invasive surgery, urinary bladder, cortisol, C-reactive protein, interleukin-6

Cystostomy is a common surgical procedure performed in the management of several conditions affecting the urinary system, including urolithiasis (Ewoldt et al. 2006, 2008; Franz et al. 2009; Defarges et al. 2013), urethral injuries (Rakestraw et al. 1995), neurogenic bladder atony (Boothe 2000), and transitional cell carcinoma (Henry et al. 2003; Smith et al. 1995). In experimental animal models, cystostomy is performed to measure the urine output, generally via celiotomy (Lond on et al. 2000; Nieuw oudt et al. 2006; Arkadopoulos et al. 2011; Nastos et al. 2011).

Minimally invasive surgery is known to be associated with early recovery and less pain compared to open surgery (Boothe 2000; Ewoldt et al. 2006; Mathon et al. 2009; Lansdowne et al. 2012; Azzouni et al. 2013). Studies have shown that the serum concentrations of interleukin-6 (IL-6) and C-reactive protein (CRP) are lower for laparoscopic procedures than for open surgeries (Cho et al. 1994; Halevy et al. 1995; Maruszynski and Pojda 1995; Karayiannakis et al. 1997; Hildebrandt et al. 2003). On the other hand, some studies have shown no significant differences between the two surgical approaches in the surgical stress response, which is measured in terms of cortisol (COR) concentrations (Jakeways et al. 1994; Targarona et al. 1996; Saga on et al. 2000). In this study, we introduce a laparoscopic technique for performing percutaneous tube cystostomy in healthy male pigs. Additionally, we sought to compare the surgical stress induced by the laparascopic and open surgical approaches for cystostomy and determine whether minimally invasive bladder surgery is beneficial for the animal models used in investigations of conditions affecting the urinary system.

Address for correspondence:

Hong-bin Wang

College of Veterinary Medicine

Northeast Agricultural University

No. 59 Mucai Street, Harbin 150030, China

Phone: +8618745051429

E-mail: hbwang1940@126.com

http://actavet.vfu.cz/ 


\section{Animals}

\section{Materials and Methods}

Fourteen healthy male Bama miniature pigs were the subjects of these studies. The mean age of these pigs was 4 (range 3-6) months and weight was 21.4 (range 15.5-25.8) $\mathrm{kg}$ at the start of the study. They were randomly divided into two groups: one underwent laparoscopic cystostomy (LC group; $n=7$ ) and the other underwent open surgical cystostomy (OC group; $n=7$ ). The pigs were housed individually and fed a standard piglet diet and tap water ad libitum. Care and handling of the animals were in accordance with regulations for the administration of affairs concerning experimental animals (Approved by the State Council on October 31, 1988 and promulgated by Decree No. 2 of the State Science and Technology Commission on November 14, 1988). Approval of the experimental protocol was obtained from the Northeast Agricultural University Ethics Committee.

\section{Anaesthetic protocol}

Food and water were withheld for 12 and $6 \mathrm{~h}$ before the surgery to minimize the risk of damage to the viscera during the placement of the cannula. Anaesthesia for each procedure consisted of a mixture of tiletamine/ zolazepam (3.0 mg/kg; Zoletil ${ }^{\circledR} 100$; Virbac Corporation, Carros, France), xylazine (1.2 mg/kg; Rompun ${ }^{\circledR}$, Bayer, Germany), and tramadol (1.6 mg/kg; Tramal ${ }^{\circledR} 100$; Grunenthal GmbH, Germany) intramuscularly (Lu et al. 2010). The animal was intubated with a $6.0-\mathrm{mm}$ tracheal tube and mask ventilation with $100 \%$ oxygen. Physiological indicators including the heart rate, arterial blood pressure, arterial haemoglobin oxygen saturation, respiratory rate, and rectal temperature were measured continuously with a non-invasive monitor (Philips IntelliVue MP30; Philips Medizin Systeme Boeblingen $\mathrm{GmbH}$, Germany). Body temperature was maintained between $36{ }^{\circ} \mathrm{C}$ and $38^{\circ} \mathrm{C}$ by warming the operating table and using an infrared heating lamp. Throughout the procedure, saline $(0.9 \% \mathrm{NaCl})$ was continuously infused at a rate of $3 \mathrm{ml} / \mathrm{kg} / \mathrm{h}$ via the marginal ear vein of the pig, and vital signs were continuously monitored with a Philips IntelliVue MP30 monitor.

\section{Surgical technique}

All the surgical procedures were performed with the pigs placed in dorsal recumbency. The ventral aspect of the abdomen was then aseptically prepared and draped for the surgery. For the LC, three portals were created: one for the laparoscope (portal 1) and two for the surgical instruments (portals 2 and 3). Portal 1 was placed at a distance of $2-3 \mathrm{~cm}$ cranially to the umbilicus, while portals 2 and 3 were placed $8-10 \mathrm{~cm}$ to the right and left of the ventral midline, respectively, and $6-8 \mathrm{~cm}$ caudally to portal 1 . The entire procedure was completed by a surgeon and 2 assistants.

A skin incision of a length of $10 \mathrm{~mm}$ was made at the site for portal 1, through which a Veress needle was inserted perpendicular to the abdominal wall. The needle was then attached to a 5-ml syringe filled to capacity with saline, and its positioning within the abdominal cavity was verified by the aspiration and injection test. Pneumoperitoneum was then established by insufflation of carbon dioxide directly through the Veress needle until the intra-abdominal pressure reached $12 \mathrm{~mm} \mathrm{Hg}$. The needle was then removed, and a trocar-cannula unit (Olympus Corporation, Tokyo, Japan) of a diameter of 10-11 mm was inserted through the abdominal wall at portal site 1 . The insufflator was connected to the cannula to maintain the intra-abdominal pressure at $12 \mathrm{~mm}$ $\mathrm{Hg}$. The trocar was then replaced with a laparoscope $\left(10 \mathrm{~mm}, 0^{\circ}\right.$; Olympus Corporation, Tokyo, Japan $)$ and the abdominal cavity briefly explored. Thereafter, the surgical table was tilted to a $30^{\circ}$ head-down position (Trendelenburg position) to displace the abdominal viscera cranially until the urinary bladder could be clearly visualized. Accessory trocar-cannula units (Olympus Corporation, Tokyo, Japan) of a diameter of 5-5.5 mm were inserted at portals 2 and 3 under laparoscopic guidance to avoid visceral injury.

The bladder was then emptied using an 18-gauge spinal needle connected to a 50-ml syringe, which was inserted through portal 2 . Then, sterile saline solution was injected through the needle to moderately distend the bladder. Next, a 3/8-circle curved needle attached to a $30-\mathrm{cm}$ piece of 2-0 polyglycolic acid suture material was grasped by a laparoscopic needle holder (diameter, $5 \mathrm{~mm}$; length, $330 \mathrm{~mm}$; Olympus Corporation, Tokyo, Japan) and inserted through portal 2. A pair of laparoscopic grasping forceps (diameter, $5 \mathrm{~mm}$; length, $330 \mathrm{~mm}$; Olympus Corporation, Tokyo, Japan) was introduced at portal 3 . The curved needle was passed through the rectus abdominis muscle in a dorsoventral direction and introduced back, at a lower site, into the seromuscular layer of the ventral aspect of the apex of the urinary bladder. For the first suture, the intra-abdominal pressure was decreased to $8 \mathrm{~mm} \mathrm{Hg}$ to reduce the tension between the ventral body wall and the urinary bladder. A simple interrupted suture was placed by using an intracorporeal suturing technique. The intra-abdominal pressure was then restored to $12 \mathrm{~mm} \mathrm{Hg}$ and maintained at this level for the next three sutures. A simple interrupted suture was placed by using the same technique used for the first suture at a distance of approximately $2 \mathrm{~cm}$ from the first suture in a transverse direction. The first two sutures attached the caudal aspect of the urinary bladder to the ventral body wall (Plate VI, Fig. 1). A purse-string suture was then placed in the ventral part of the urinary bladder wall approximately $1 \mathrm{~cm}$ cranial to the fixation point of the urinary bladder. The laparoscopic needle holder at portal 2 was replaced by a laparoscopic scalpel to make a stab incision on the bladder wall at the center of the purse-string suture. A paramedian stab incision was then made in the ventral body wall approximately $1 \mathrm{~cm}$ laterally to the ventral midline. A 12-F Foley catheter was advanced through the stab incision by using a laparoscopic needle holder (Plate VI, Fig. 1). The balloon of the Foley catheter was inflated with injection of $3 \mathrm{ml}$ of sterile saline to secure it within the urinary bladder; the purse-string suture was then pulled and tied. Subsequently, the catheter was pulled close to the body wall, and two more sutures were placed between the 
urinary bladder and the ventral body wall at a distance of $1 \mathrm{~cm}$ cranially to the catheter to create a cystopexy (Plate VI, Fig. 2). Saline was then injected into the bladder to check for the bladder patency and rule out urine leakage. The extracorporeal portion of the catheter was then secured to the skin by a finger-trap suture and its free end attached to a closed urine collection bag. All the portals were closed in two layers. All the OC surgeries were performed by the same surgeon with technical assistance.

\section{Postoperative care}

Since the start of the procedures, vital indicators (temperature, heart rate, respiratory rate, and arterial blood pressure) of the pigs were monitored until the values returned to the preoperative levels and the animals regained consciousness. Buprenorphine (0.01 mg/kg i.m.; Hansen Pharma Co., Ltd., Changsha, China) was administered after the induction of general anaesthesia to alleviate postoperative pain. For antibiotic coverage, ampicillin (20 mg/kg i.m.; Lukang Pharma, Jining, China) was administered intramuscularly every 8 h for 3 days. The pigs were housed individually to avoid damage to the catheters by the other pigs. All the pigs underwent a thorough clinical examination as well as the measurement of complete blood cell (CBC) every day. The extracorporeal catheter portion of the catheter was cleaned every day, and the urine collection bag was emptied twice a day in a sterile manner. The catheter was removed on postoperative day 10. Repeat laparoscopy was performed one month after the surgery to reevaluate the status of the entire abdominal cavity and associated viscera. Followup necropsy was performed 3 months after the surgery; the animals were euthanized with Pentothal (Sodium pentothal, Janssen Pharma, China) induction and potassium chloride injection.

\section{Serum CRP, IL-6, and COR concentrations}

Blood samples $(2.5 \mathrm{ml})$ were collected in dry tubes from the precaval vein of the pigs at the following time points: $1 \mathrm{~h}$ before surgery; $4 \mathrm{~h}$ after surgery; and 1,2,3,5, and 7 days after the surgery. The blood samples were centrifuged for $10 \mathrm{~min}$ at $3000 \times \mathrm{g}$, with the serum aliquoted into two Eppendorf tubes and immediately stored at $-80{ }^{\circ} \mathrm{C}$. The serum concentrations of CRP, IL-6, and COR were measured by using enzyme-linked immunosorbent assay kits (YaPu Biological Technology Co., Ltd, Shanghai, China) for porcine C-reactive protein (sensitivity, $0.1 \mathrm{mg} / \mathrm{l}$ ), interleukin-6 (sensitivity, $0.1 \mathrm{pg} / \mathrm{ml}$ ), and cortisol (sensitivity, $1.0 \mathrm{ng} / \mathrm{ml}$ ).

\section{Statistical analysis}

One-way analysis of variance was performed by the SPSS software (version 17.0; SPSS Institute, Cary, NC, USA) to determine the significance of inter- and intragroup differences. Significance of differences was set at a $P$ value of $<0.05$. The data were expressed as mean \pm standard error of the mean (SEM).

\section{Results}

\section{Surgical procedure and clinical outcome}

Laparoscopic cystostomy was successfully performed in all the pigs, without any major intraoperative or postoperative complications. The LC and the OC groups did not show any significant differences in the operative time ( $43 \pm 5 \mathrm{~min}$ vs. $37 \pm 5 \mathrm{~min}$, respectively). However, considering that the LC operative time was reduced by $16 \mathrm{~min}$ with increasing experience, we believe that further reduction in the operating time may be possible with additional practice.

All the pigs recovered from anaesthesia within $30 \mathrm{~min}$ of the completion of the surgery. Intraoperative bleeding was negligible in all the cases. The total length of the skin incision for the LC procedure was $2 \mathrm{~cm}$ (including incisions for all three portals), which was significantly smaller than that recorded for the OC group $(10 \pm 2 \mathrm{~cm} ; P<0.01)$. The 24-h urine outputs in the LC and OC groups were approximately $498 \pm 56 \mathrm{ml}$ and 512 $\pm 35 \mathrm{ml}$, respectively. Repeat trocarization was required in one case for the laparoscopic forceps, while subcutaneous emphysema was noted in another case. No other perioperative complications were noted.

The pigs in the LC group showed signs of slight abdominal discomfort after the operation; their body temperatures remained normal throughout the observation period, and their appetite returned to normal within $24 \mathrm{~h}$ of the surgery. Further, none of the LCgroup pigs showed any signs of irritation at the stoma site or intraperitoneal urine leakage while the catheters were in place. Similar findings were noted in the case of animals in the OC group. Additionally, accidental dislodgment or damage did not occur in any case. The urinary function returned to normalcy in all the pigs after removal of the urinary catheter on 
postoperative day 10 . These results suggest that the postoperative discomfort and recovery after LC was similar to that after OC.

Repeat laparoscopy was performed 1 month after the surgery and showed no signs of peritonitis in any of the pigs of the LC group. The only abnormalities noted on the followup laparoscopy were focal fibrous adhesions (Plate VII, Fig. 3) between the urinary bladder and the ventral body wall in the pigs of the LC group. In all the animals, the abdominal serosa was pink, and the trocar sites appeared as white or reddish, oval, and raised structures, indicating advanced peritoneal healing. No complications occurred within 3 months of the

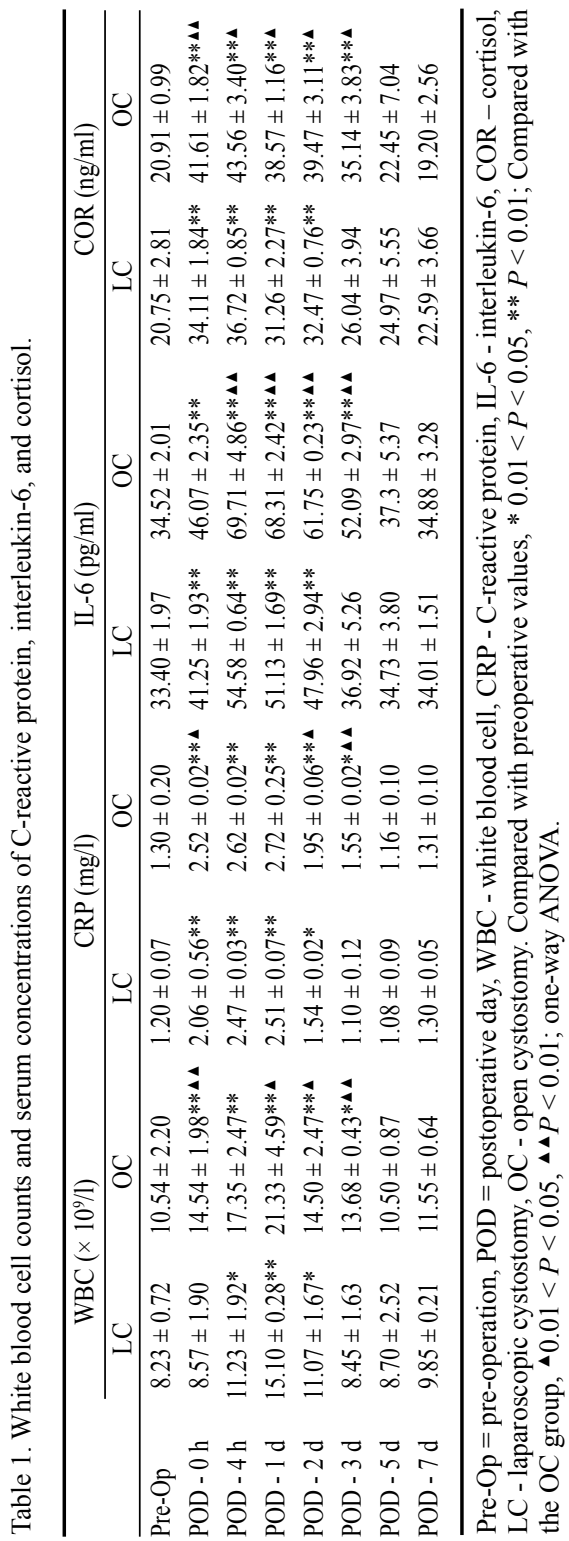
surgery until the animals were euthanized with administration of a pentothal and potassium chloride injection. These findings indicate that the postoperative healing in the LC group was similar to that in the OC group.

\section{White blood cell counts}

After the surgery, the mean white blood cell (WBC) counts increased significantly from $8.23 \pm 0.72$ to $15.1 \pm 0.28 \times 10^{9} / 1(P<0.01)$ in the LC group and from $10.54 \pm 2.20$ to 21.33 $\pm 4.59 \times 10^{9} / 1$ in the TC group, at $24 \mathrm{~h}$ after the surgery. Even after the increase, the WBC counts in both groups were within the reference interval $\left(11-22 \times 10^{9} / 1\right)$ defined for the automated device used for the measurement. The WBC count returned to the preoperative levels on postoperative day $3(8.45 \pm 1.63 / 1$, $P>0.05)$ in the LC group and postoperative day $5(10.5 \pm 0.87 / 1, P>0.05)$ in the OC group, thereby showing an earlier return to normalcy in the LC group (Table 1).

\section{Serum CRP, IL- 6 and COR concentrations}

In the serum CRP concentrations in the LC group, significant differences from the preoperative levels $(1.20 \pm 0.07 \mathrm{mg} / \mathrm{l})$ were noted at $0 \mathrm{~h}(2.06 \pm 0.56 \mathrm{mg} / \mathrm{l}, P<0.01), 4 \mathrm{~h}$ $(2.47 \pm 0.03 \mathrm{mg} / \mathrm{l}, P<0.01)$, and $24 \mathrm{~h}(2.51 \pm$ $0.07 \mathrm{mg} / \mathrm{l}, P<0.01)$ after the surgery; the serum CRP concentration was the highest at $24 \mathrm{~h}$ after the surgery. Compared to the OC group, the LC group showed a slower increase in CPR concentrations in the LC group and a more rapid return to the basal concentrations (Table 1).

Serum IL-6 concentrations in the LC group showed an increase immediately after the surgery and reached the highest level $(54.58 \pm$ $0.64 \mathrm{pg} / \mathrm{ml}$ ) at $4 \mathrm{~h}$ after the surgery compared to the preoperative levels $(33.40 \pm 1.97 \mathrm{pg} / \mathrm{ml}, P<$ $0.01)$. The decrease in the IL-6 concentrations occurred more rapidly in the LC group compared to the OC group (Table 1). 
In both groups, the mean serum COR concentrations increased immediately after the surgery $(34.11 \pm 1.84 \mathrm{ng} / \mathrm{ml}$ and $41.61 \pm 1.82 \mathrm{ng} / \mathrm{ml}$ for the LC group and the OC group, respectively) and did not show any significant differences at any time point (Table 1).

\section{Discussion}

Minimally invasive laparoscopic surgery is rapidly gaining popularity worldwide. Laparoscopic procedures have been shown to require smaller surgical incisions than open surgical procedures and obviate the need for extensive manual traction on the bladder in comparison to open approach (Rocken et al. 2006). However, the stress response induced by the longer operative time and by the different steps in the laparoscopic procedure, including the establishment of a pneumoperitoneum, has not yet been sufficiently evaluated. CRP is a highly sensitive marker of acute inflammation, tissue damage, sepsis, and postoperative complications (Eckersall et al. 1989; Yamamoto et al. 1993; Dabrowski et al. 2007). Serum IL-6 concentrations can be used for the assessment of the extent of surgical trauma (Mathon et al. 2009). Our study results indicated that the serum concentrations of CRP and IL-6 after conventional cystostomy were significantly higher than those after LC. However, the metabolic response appeared to be similar for both operative techniques, as indicated by the similar serum concentrations of COR noted in both groups. These findings are consistent with those previously reported for the stress response to laparoscopic and open cholecystectomy (Sagaon et al. 2000). Together, our results suggest that the degree of stress induced by LC is lesser than that induced by OC. We believe that the clinical advantages of LC over OC may be partly attributed to a reduced surgical response, as indicated by the reduced physiological effect, which in turn may also minimize postoperative discomfort.

Maintaining the intra-abdominal pressure at $12 \mathrm{~mm} \mathrm{Hg}$ allowed for good separation of the contents of the pelvic cavity from the abdominal viscera and provided sufficient space to perform surgery. The locations selected for the creation of the portal access for the optic trocar as well as the use of the grasping forceps facilitated an easy grasping of the bladder, without any complications. The placement of portal 1 for the laparoscope at a distance of $2-3 \mathrm{~cm}$ cranially to the umbilicus allowed for excellent visualization of the urinary bladder and related structures. Portals 2 and 3 for the instruments were located 16-18 cm caudal to the laparoscope portal and $10-12 \mathrm{~cm}$ to the right and left of the midline, respectively. This triangular positioning of the three portals enabled easy manipulation of the urinary bladder. The cause of subcutaneous emphysema was probably the increased length of the incision made for the trocar. Instances of repeat trocarization with the grasping forceps were mainly due to the surgeon's lack of experience as an endoscopist. It is expected that the operative time for LC may decrease further as the surgeon gains more experience.

The traditional approach for LC is to insert the catheter into the urinary bladder through a stab incision made within a purse-string suture, which is then pulled tightly and tied to fix the catheter to the urinary bladder wall; the bladder is then approximated to the ventral abdominal wall and the extracorporeal portion of the catheter fixed to the skin by the Chinese finger-trap suture (Ewoldt et al. 2006; Iselin et al. 2001). In our technique of $\mathrm{LC}$, four simple interrupted sutures were placed within the body cavity in addition to the single purse-string suture. The four simple interrupted sutures allow for a secure fixation of the urinary bladder to the ventral body wall, thereby minimizing the risk of abdominal leakage of urine. Although the additional sutures may help firmly secure the bladder in its position, further precautions need to be taken. One is that the Chinese finger-trap ligature should be strong enough to avoid the kinking of the catheter, which is fairly common; this ligature also prevents damage or shift of the catheter. Another important consideration when 
performing LC on experimental animal models is that the animals should be individually housed to avoid damage to the catheter by other pigs.

In all the pigs of both the groups, repeat laparoscopy showed the presence of focal fibrous adhesions between the urinary bladder and the ventral body wall. These adhesions prevent urinary leakage into the abdominal cavity.

One of the limitations of this study is that we did not perform bacterial culture studies on the urine samples of the pigs. However, the CBC results and CRP concentrations were within the reference range when evaluated at 5 postoperative days, and all the pigs had completely regained their appetite at $24 \mathrm{~h}$ after the operation. Additionally, the pigs did not develop any complications of the urinary system within the next three months. Therefore, it may be reasonable to infer that major infective complications were absent.

In conclusion, we described a LC technique using a 3-portal approach and found that this technique elicited a lower stress response than OC. The method also appeared to be feasible from both the technical as well as physiological standpoints. This minimally invasive technique for performing cystostomy in swine could enable the establishment of useful animal models for use in studies on diseases affecting the urinary system and other medical conditions that require temporary or permanent diversion of urine flow.

\section{Acknowledgements}

This work was financially supported by grants from the Research Fund for the Doctoral Program of Higher Education of China (No. 20102325110003) and the Postgraduate Innovation Fund of Hei Long Jiang Province (YJSCX2012-040HLJ).

\section{References}

Arkadopoulos N, Defterevos G, Nastos C, Papalois A, Kalimeris K, Smrniotis V 2011: Development of a porcine model of post-hepatectomy liver failure. J Surg Res 170: e233-e242

Azzouni F 2013: Current status of minimally invasive radical cystectomy: an outcome-based comparison. Expert Rev Anticancer Ther 13: 681-95

Boothe HW 2000: Managing traumatic urethral injuries. Clin Tech Small An P 15: 35-39

Cho JM, LaPorta AJ, Claek JR, Schofield MJ, Harmmond SL, Mallory PL 1994: Response of serum cytokines in patients undergoing laparoscopic cholecystectomy. Surg Endosc 8: 1380-1384

Dabrowski RW, Wawron W, Kostro K 2007: Changes in CRP, SAA and haptoglobin produced in response to ovariohysterectomy in healthy bitches and those with pyometra. Theriogenology 67: 321-327

Defarges A, Dunn M, Berent A 2013: New alternatives for minimally invasive management of uroliths: lower urinary tract uroliths. Compend Contin Educ Vet 35: E1

Eckersall PD, Conner JG, Parton H 1989: An enzyme-linked immunosorbent assay for canine C-reactive protein. Vet Rec 124: 490-491

Ewoldt JM, Anderson DE, Miesner MD, Saville WJ 2006: Short- and long-term outcome and factors predicting survival after surgical tube cystostomy for treatment of obstructive urolithiasis in small ruminants. Vet Surg 35: 417-422

Ewoldt JM, Jones ML, Miesner MD 2008: Surgery of obstructive urolithiasis in ruminants. Vet Clin Food Anim 24: $455-465$

Franz S, Dadak AM, Schoffmann G, Khol JL, Baumgartner W, Dupre G 2009: Laparoscopic-assisted cystotomy: an experimental study in male sheep. Vet Med 54: 367-373

Halevy A, Lin G, Gold-Deutsch R, Lavi R, Negri M, Evans S, Cotariu D, Sackier JM 1995: Comparison of serum C-reactive protein concentrations for laparoscopic versus open cholecystectomy. Surg Endosc 9: 280-282

Henry CJ 2003: Management of transitional cell carcinoma. Vet Clin North Am Small Anim Pract 33: 597-613

Hildebrandt U, Kessler K, Plusczyk T, Pistorius G, Vollmar B, Menger, D 2003: Comparison of surgical stress between laparoscopic and open colonic resections. Sur Endosc 17: 242-246

Iselin U, Braun U, Steiner A, Lischer C 2001: Cystostomy with and without temporary implantation of an urinary balloon catheter for treatment of obstructive urolithiasis in small ruminants: a retrospective study. Vet Med Austria 88: $39-45$

Jakeways MR, Mitchell V, Hashim IA, Chadwick SD, Shenkin A, Green CJ, Carli F 1994: Metabolic and inflammatory responses after open or laparoscopic cholecystectomy. Br J Surg 81: 127-131

Karayiannakis AJ, Makri GG, Mantzioka A, Karousos D, Karatzas G 1997: Systemic stress response after laparoscopic or open cholecystectomy: a randomized trial. Br J Surg 84: 467-471

Lansdowne JL, Mehler SJ, Bouré LP 2012: Minimally invasive abdominal and thoracic surgery: techniques. Compend Contin Educ Vet 34: E2 
London ET, Ho HS, Neuhaus AM, Wolf BM, Rudich SM, Perez RV 2000: Effect of intravascular volume expansion on renal function during prolonged $\mathrm{CO}_{2}$ pneumoperitoneum. Ann Surg 231: 195-201

Lu DZ, Fan HG, Wang H, Hu K, Zhang JT, Yu SM 2010: Effect of the addition of tramadol to a combination of tiletamine-zolazepam and xylazine for anaesthesia of miniature pigs. Vet Rec 167: 489-492

Maruszynski M, Pojda Z 1995: Inerleukin 6 (IL-6) levels in the monitoring of surgical trauma. A comparison of serum IL-6 concentrations in patients treated by cholecystectomy via laparotomy or laparoscopy. Surg Endosc 9: $882-885$

Mathon DR, Dossin O, Palierne S, Cremoux M, Rodriguez H, Lefebver H, Autefage A 2009: A laparoscopicsutured gastropexy technique in dogs: mechanical and functional evaluation. Vet Surg 38: 967-974

Nastos C, Kalimeris K, Papoutsidakis N, Defterevos G, Smyrniotis V, Arkadopoulos N 2011: Antioxidant treatment attenuates intestinal mucosal damage and gut barrier dysfunction after major hepatectomy: study in a porcine model. J Gastrointest Surg 15: 809-817

Nieuwoudt M, Kunnike R, Smuts M, Becker J, Stegmann GF, Walt CV, Neser J, Merwe SV 2006: Standardization criteria for an ischemic surgical model of acute hepatic failure in pigs. Biomaterials 27: 3836-3845

Rakestraw PC, Fubini SL, Gilbert RO, Ward JO 1995: Tube cystostomy for treatment of obstructive urolithiasis in small ruminants. Vet Surg 24: 498-505

Rocken M, Stehle CH, Mosel G, Rass J, Lizke LF 2006: Laparoscopic-assisted cystotomy for urolith removal in Geldings. Vet Surg 35: 394-397

Sagaon MM, Hanly EJ, Talamini MA, Kutka MF, Gitzelmann CA, Suquet KH, Poulose BF, Paidas CN, Maio AD 2000: Comparison of the stress response after laparoscopic and open cholecystectomy. Surg Endosc 14: $1136-1141$

Smith JD, Stone EA, Gilson SD 1995: Placement of a permanent cystostomy catheter to relieve urine outflow obstruction in dogs with transitional cell carcinoma. J Am Vet Med Assoc 206: 496-499

Targarona EM, Pons MJ, Balague C, Espert JJ, Moral A, Martinez J, Gaya J, Filella X, Rivera F, Ballesta A, Trias M 1996: Acute phase is only significantly reduced component of the injury response after laparoscopic cholecystectomy. World J Surg 20: 528-534

Yamamoto S, Shida T, Miyaji S, Santsuka H, Fujise H, Mukawa K, Furukawa E, Nagae T, Naiki M 1993: Changes in serum C-reactive protein levels in dogs with various disorders and surgical traumas. Vet Res Commun 17: $85-93$ 


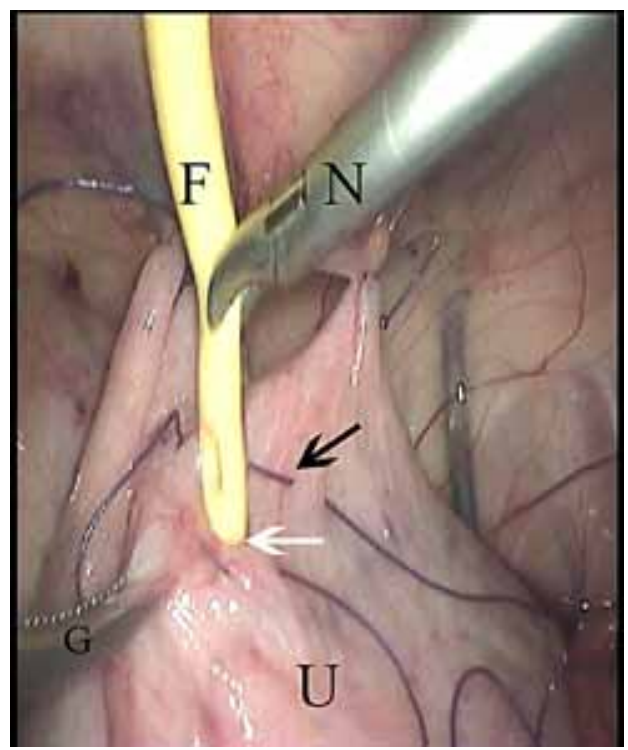

Fig. 1. Intraoperative view. Two simple interrupted sutures were used to attach the caudal aspect of the urinary bladder $(\mathrm{U})$ to the ventral body wall. A laparoscopic needle holder $(\mathrm{N})$ was used to assist the advancement of the Foley catheter $(\mathrm{F})$ into the urinary bladder through a stab incision (white arrow) made at the center of the purse-string suture (black arrow). $\mathrm{G}=$ grasping forceps.

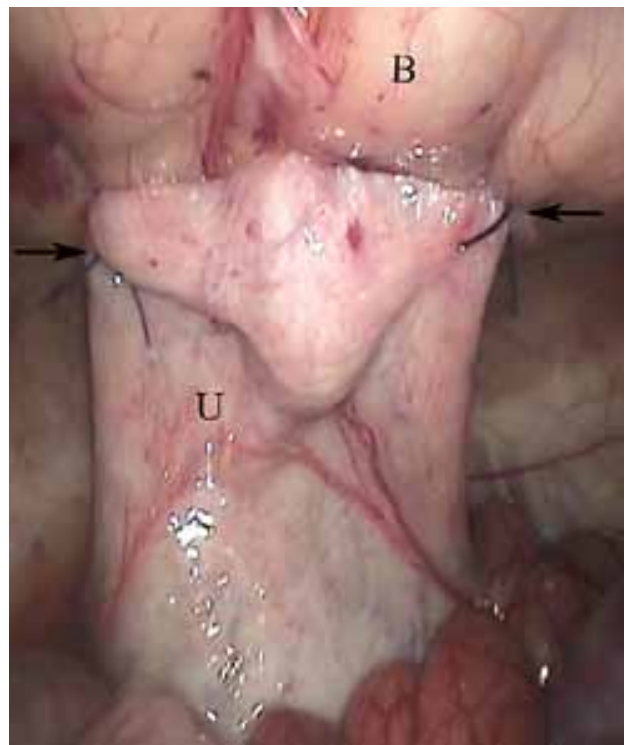

Fig. 2. Intraoperative view. The Foley catheter was pulled close to the body wall (white arrow), and two other sutures (black arrow) were placed between the urinary bladder (U) and the ventral body wall (B) to create cystopexy. 


\section{Plate VII}

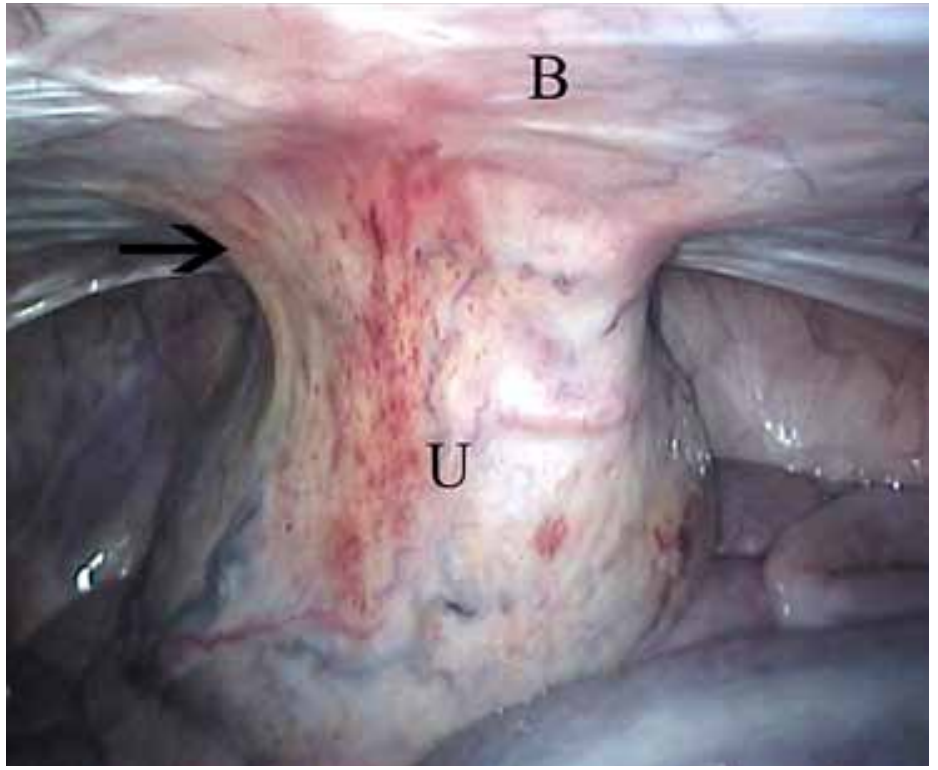

Fig. 3. During the repeat laparoscopy performed one month after the surgery, focal fibrous adhesions (black arrow) were noted between the urinary bladder (U) and the ventral body wall (B). 